\title{
Economic Dispatch Analysis of Hybrid Power Plant System in Islands Area Based on Linear Programming Method
}

\author{
Rusdianto ${ }^{1}$, Eddy Setyo Koenhardono ${ }^{2}$, Juniarko Prananda ${ }^{3}$ \\ (Received: 03 August 2019 / Revised: 15 December 2020 / Accepted: 20 December 2020)
}

\begin{abstract}
Selatpanjang, Meranti Island Regency, Riau continues to occur. However, the availability of diesel fuel types is increasingly scarce and the price is increasingly expensive. Therefore, another generator is needed, namely a relatively cheap coal-fired power plant and the availability of coal reserves in the Sumatran region. One of the problems in the economic operation of a generating system is economics dispatch, which is how to obtain minimum operating costs while meeting existing and reliable limits. For this reason, an economic dispatch analysis is needed for the optimal generating system by using the linear programming method. This economic dispatch analysis uses operational cost as a parameter and is done by using software assistance in the form of Matlab. Based on the results of loading with the same variation, the power generation based on economic dispatch calculations has an average load factor smaller than the average load factor based on unit commitment improvement calculations. Thus, the generation with economic dispatch has a higher specific fuel consumption $(\mathrm{g} / \mathrm{KWH})$ than the unit commitment improvement so that the fuel consumption price is issued higher.
\end{abstract}

Keywords-economic dispatch, unit commitment improvement, linear programming, load factor.

\section{INTRODUCTION}

E lectricity needs in the Selatpanjang area, Meranti Island Regency, Riau continue to increase with an average of $6.54 \%$ per year and until now only supplied by Diesel Power Plants (PLTD) [1]. At the same time, the availability of diesel fuel types is increasingly scarce and the price is relatively expensive. Therefore, the use of alternative power plants is needed so that electricity needs in the Selatpanjang region, Meranti Island Regency, Riau can be fulfilled. The alternative generator is considered relevant if applied in the Selatpanjang area, namely coalfired Steam Power Plant (PLTU). This is due to the availability of coal resources in the Sumatran region in 2017 , which is $36.72 \%$ or $45,969.24$ million tons of total national coal resources, while coal reserves are around $40.88 \%$ or $9,909.1$ million tons [2]. Plus the price of coal fuel is lower than natural gas in the interest of electricity, which is USD 70 / metric ton with a calorie level of 6,322 $\mathrm{kcal} / \mathrm{kg} \mathrm{GAR}$, equivalent to USD 3.08 / MMBtu, while the natural gas price of the region 2 (southeast Sumatra and south), which is USD 6.05 / MMBtu [3].

The limited availability and high prices of fossil fuels for this need to be carried out by the operating system management of the generating system. Where one of the problems in the economic operation of a power plant is economics dispatch, which is how to get a minimum operating cost while still meeting existing and reliable limits [4-9]. To solve all these problems, it is necessary to do an economic dispatch analysis for generating systems

Rusdaianto, Department of Marine Engineering Institut Teknologi Sepuluh Nopember Surabaya, 60111, Indonesia. Email rusdianto163@gmail.com

Eddy Setyo Koenhardono, Department of Marine Engineering Institut Teknologi Sepuluh Nopember Surabaya, 60111, Indonesia. Email: eddyk@its.ac.id

Juniarko Prananda, Department of Marine Engineering Institut Teknologi Sepuluh Nopember ITS Surabaya, 60111, Indonesia. Email: juniarko.prananda@gmail.com that are suitable for the Selatpanjang, Meranti Islands Regency, Riau.

\section{METHOD}

In this study, economic dispatch analysis was carried out using linear programming methods and assisted by the Matlab application. The output of linear programming is in the form of incremental power.

\section{A. Economic Dispatch}

Economic Dispatch is the process of determining the output power produced by a unit or system unit to supply the specified load by minimizing the total fuel cost [4-9]. The amount of the total power produced by the power generation system must be the same as the load demand. In simplified cases, transmission losses are ignored. This makes the task procedure solution easier. The practice, transmission losses must be considered [4].

Figure 1 shows the configuration of this system which consists of $\mathrm{N}$ power generating units connected to a single busbar that supplies the $P_{\text {load }}$ electric load. The input for each unit, shown as $\mathrm{Fi}$, represents the cost rate of unit $\mathrm{i}$. The output of each unit, $P_{i}$, is the electrical power produced by unit I itself. The level of the total cost of this system is the sum of the costs of each unit.

1) The cost function

The fuel cost function is usually estimated as a quadratic equation, this is the objective function [5]:

$F_{i}=\sum_{i=1}^{N}\left(a_{i}+b_{i} P_{i}+d_{i} P_{i}^{2}\right)$

Where:

$\mathrm{F} \quad=$ fuel cost

$\mathrm{N}=$ total number of units 


$$
\begin{array}{ll}
\mathrm{i} & =\text { unit index } \\
\mathrm{P} & =\text { output power }
\end{array}
$$

$\mathrm{a}, \mathrm{b}, \mathrm{d}=$ coefficient of function of fuel cost

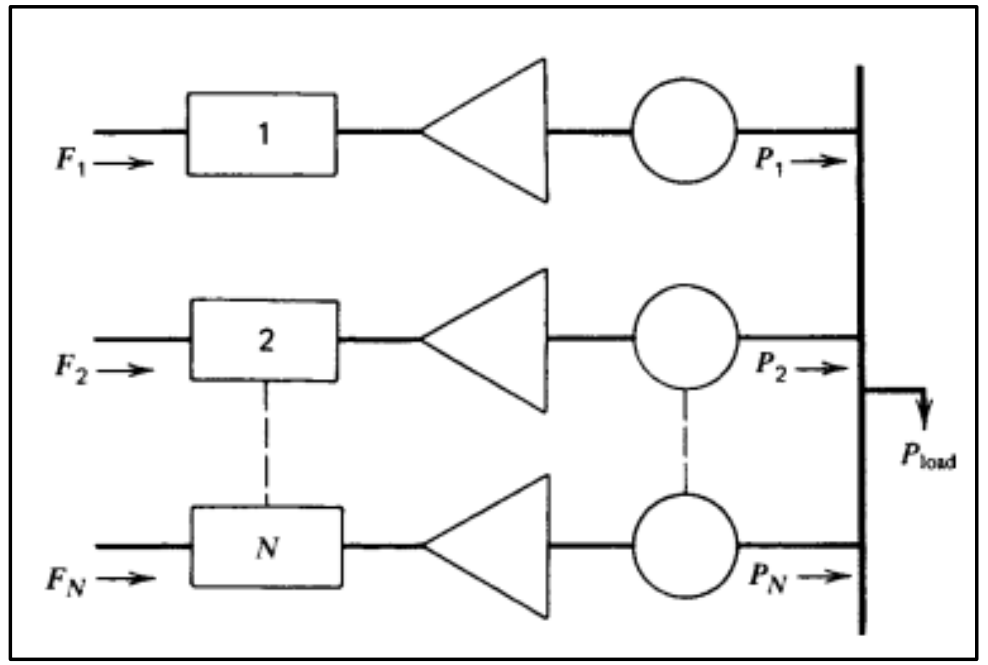

2) Equality constraints

Figure. 1. $\mathrm{N}$ units committed to serving a load of $P_{\text {load }}$ [4]

The total amount of power generated by the generating system must be equal to the load supplied, along with its objective function [4] [9]:

$\sum_{i=1}^{N}\left(P_{i}\right)=$ Load

Where:

Load $=$ total load system

$P_{i} \quad=$ output power of unit $\mathrm{i}$

3) Inequality constraints

Each power output is limited by the following upper and lower limits [4] [9]:

$P_{i \min } \leqslant P_{i} \leqslant P_{i \max }$

Where:

$P_{i \min }=$ minimum power limit of unit $\mathrm{i}$

$P_{i \text { max }}=$ maximum limit of unit i

B. Linear Programming ( LP)

Linear programming, also called linear optimization is a method for achieving the best results (such as maximum profit or lowest cost) in a mathematical model whose requirements are represented by a linear relationship [10]. Linear programming is one of the preferred methods for optimizing power system problems. The size and complexity of such multi-variable, multiconstraint problems call for the use of LP solvers [11] [12]. The following steps are for doing linear programming:

1) Linear Model

The objective function of linear programming to be used is the sum of the fuel cost curve approach. However, in minimizing this objective function, the first term, namely $\mathrm{F}\left(P_{\text {imin }}\right)$ will not be included in the linear programming formulation. This is because $\mathrm{F}\left(P_{\text {imin }}\right)$ is a constant value so that it does not have an influence on the values of decision variables in linear programming. However, if to value or express the objective function of the total fuel cost used, then the value of $\mathrm{F}\left(P_{\text {imin }}\right)$ must be put back into the objective function of fuel costs [4].

A quadratic function can be carried out by a linear function approach as a series of straight-line segments shown in Figure 2 [4] [13]. Three segments for generator $\mathrm{i}$ will be represented as $i 1, i 2$, and $i 3$. The $\mathrm{Pi}$ variable is replaced by three new variables $P_{i 1}, P_{i 2}$, and $P_{i 3}$. Each segment will have a slope designed as $C_{i l}$, $C_{i 2}$, and $C_{i 3}$. Thus, the objective functions of the linear program are shown as ' $Z$ ' values as follows [4]:

$Z=\sum_{i=1}^{N} \sum_{k=1}^{j} C_{i k} x P_{i k}$

$C_{i k}=\frac{F\left(P_{i k \max }\right)-F\left(P_{i k \min }\right)}{P_{i k \max }-P_{i k \min }}$

$C_{i 1} \leqslant C_{i 2} \leqslant C_{i 3}$

Where:

$\mathrm{Z} \quad=$ total incremental cost

$\mathrm{C}=$ slope

$\mathrm{k} \quad=$ segment

j $\quad=$ total segment

If expressed in the form of a matrix, the function $\mathrm{Z}$ becomes as follows:

$Z=\left[\begin{array}{lllllllll}C_{11} & C_{12} & C_{13} & \ldots & C_{i 1} & C_{i 2} & C_{i 3} & \end{array}\right]\left[\begin{array}{c}P_{11} \\ P_{12} \\ P_{13} \\ \ldots \\ \ldots \\ \ldots \\ P_{i 1} \\ P_{i 2} \\ P_{i 3}\end{array}\right]$

Where;

$Z=C^{T} X$

So that the matrix $\mathrm{Z}$ with $\mathrm{C}$ and $\mathrm{X}$ becomes as follows:

$Z=\left[\begin{array}{c}C_{11} \\ C_{12} \\ C_{13} \\ \ldots \\ \ldots \\ \ldots \\ C_{i 1} \\ C_{i 2} \\ C_{i 3}\end{array}\right], \quad X=\left[\begin{array}{c}P_{11} \\ P_{12} \\ P_{13} \\ \cdots \\ \cdots \\ \ldots \\ P_{i 1} \\ P_{i 2} \\ P_{i 3}\end{array}\right]$

So, the total fuel cost function becomes as follows:

$\sum_{i=1}^{N} F\left(P_{i}\right)=\sum_{i=1}^{N}\left[F_{i}\left(P_{i \text { min }}\right)+\ldots\right.$

$\left.\left.\ldots \sum_{i=1}^{N} \sum_{k=1}^{j} C_{i k} x P_{i k}\right)\right]$ 
2) Upper and Lower Bound

The determination of the lower limit must consider that all variables at the level of generation must not have a negative value. Where in reality it is impossible to have a value of increasing negative generation. However, an increase in pp generation can be obtained between zero and the upper limit. While the upper limit

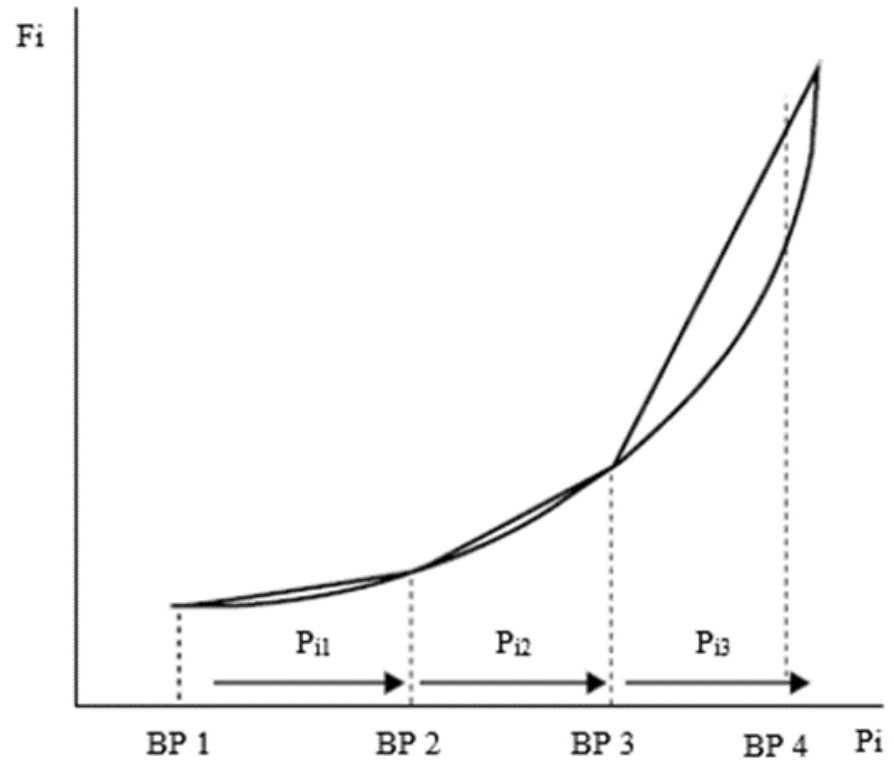

Figure. 2. Nonlinear cost function approximated by straight-line segments [4]

is the maximum increase limit by each level of unit I [14].

This limit value is obtained from the result of the reduction of BreakPoint $2\left(P_{i k \max }\right)$ by BreakPoint $1\left(P_{i k}\right.$ min) which is used as the upper limit of the first level of increase in Unit $i$. Thus, each level of generation per Unit I will have a lower and upper limit in the form of a matrix as follows:

$\left[\begin{array}{l}0 \\ 0 \\ 0 \\ 0 \\ 0 \\ 0 \\ 0 \\ 0 \\ 0\end{array}\right] \leq\left[\begin{array}{c}P_{11} \\ P_{12} \\ P_{13} \\ \vdots \\ \vdots \\ \vdots \\ P_{i 1} \\ P_{i 2} \\ P_{i 3}\end{array}\right] \leq\left[\begin{array}{ll}P_{11} \max & -P_{11 \min } \\ P_{12 \max }-P_{12 \min } \\ P_{13 \max }-P_{13 \min } \\ \vdots \\ \vdots \\ \vdots \\ P_{i 1 \max }-P_{i 1 \min } \\ P_{i 2 \max }-P_{i 2 \min } \\ P_{i 3 \max }-P_{i 3 \min }\end{array}\right]$

3) The Modified Power Balance

Power balance is a limit of equations where the total amount of power generated by all units i must be equal to the amount of load supplied. It may appear that the number $3 * P N$ which is a new variable must also be equal to the total load supplied. However, this statement is not quite correct, because the number $3^{*} P N$ which is this new variable is incremental power, where $P_{i} \min$ for each Unit $\mathrm{i}$ is not included in the calculation. Therefore, there must be a reduction in the load supplied by the total Pimin from each Unit i. Thus, equality constraints to $3 * P N$ which are new variables are as follows:

$P_{11}+P_{12}+P_{13}+\ldots+\ldots+\ldots$

$\ldots+P_{i 1}+P_{i 2}+P_{i 3}=\left(\right.$ Load $-\left(P_{1 \text { min }}+\cdots+P_{\text {imin }}\right)$
The matrix form of the above equation is as follows:

$\left[\begin{array}{ccc}1 & \vdots & 1 \\ 0 & \vdots & 0 \\ 0 & \vdots & 0 \\ \vdots & \vdots & \vdots \\ \vdots & \vdots & \vdots \\ \vdots & \vdots & \vdots \\ 0 & \vdots & 0 \\ 0 & \vdots & 0 \\ 0 & \vdots & 0\end{array}\right]\left[\begin{array}{c}P_{11} \\ P_{12} \\ P_{13} \\ \cdots \\ \cdots \\ P_{i 1} \\ P_{i 2} \\ P_{i 3}\end{array}\right]=\left[\begin{array}{c}\text { Load }-\left(\sum_{i=1}^{17} P_{\text {imin }}\right) \\ 0 \\ 0 \\ \cdots \\ \cdots \\ \cdots \\ 0 \\ 0 \\ 0\end{array}\right]$

So, the total output power for unit i become as follows:

$P_{i}=P_{i \min }+P_{i 1}+P_{i 2}+P_{i 3}$

\section{Engine Load Factor}

ISO-8528-1 stipulates the ability of an average 24-hour load factor of 70 percent for standby generators and prime generators unless a higher average is approved by the engine manufacturer. In an emergency standby application, this means that the average load factor that can be sustained by most generators during extended outages of 24 hours or more cannot exceed 70 percent of the standby rating nameplate, a factor that affects the size of the generator set. ISO-8528 defines the output power generator set category as follows [15] [16]:

1) Emergency Standby Power (ESP) Rating is the maximum amount of power that can be produced by a set of generators and is usually used to supply facility power to variable loads in the event of a blackout.

2) Prime-rated Power (PRP) generators are available for an unlimited number of hours per year in variable load applications, as long as the average load factor does not exceed 70 percent of the nameplate rank unless the manufacturer allows a higher average load factor.

3) Continuous Power Rating (COP) is used for applications where there is no electric power and 
the generator is set for all power needs. This ranking generator can supply power at a 100 percent constant rated load for an unlimited number of hours per year.

In this study, the engine load factor is set between the range of $65 \%$ to $85 \%$.

\section{Running Code}

At this stage, the program that has been made in the Matlab report is then run. The output value that comes out of this linear program is the incremental power (Pik) value of each Unit i. In this program, incremental power is symbolized by the letter ' $\mathrm{X}$ '. This ' $\mathrm{X}$ ' value is then used as a new input to find the total power that must be generated for every Unit i. Furthermore, the power values of each Unit I (Pi) obtained are used as input to find the total costs incurred to generate power for each Unit I by substituting the value of $\mathrm{Pi}$ into the function of the fuel curve equation of each Unit $i$. Thus, the expected final input is in the form of the power value of each Unit $i$ and the fuel costs incurred in the R-day period.

\section{E. Validation}

The linear program that has been created is applied by Matlab, then the validation process is carried out by using the Octave application. In the validation process, one example scenario 1 is taken with a load of $18828 \mathrm{KW}$ in the year 2026 19th hour. Where after comparing the results of the validation in the form of total fuel costs incurred the difference or error is obtained by $0.0023604 \%$. Thus, a linear program can be declared valid where the error that occurs is considered very small or not even up to $1 \%$.

\section{RESULT AND DISCUSSION}

In this study, based on the projection of electricity demand in the Selatpanjang, the Meranti Island Regency Rau shown in Figure 3, the completion of the economic dispatch system of the power plant which is then compared to the commitment improvement unit is divided into three cases as follows:

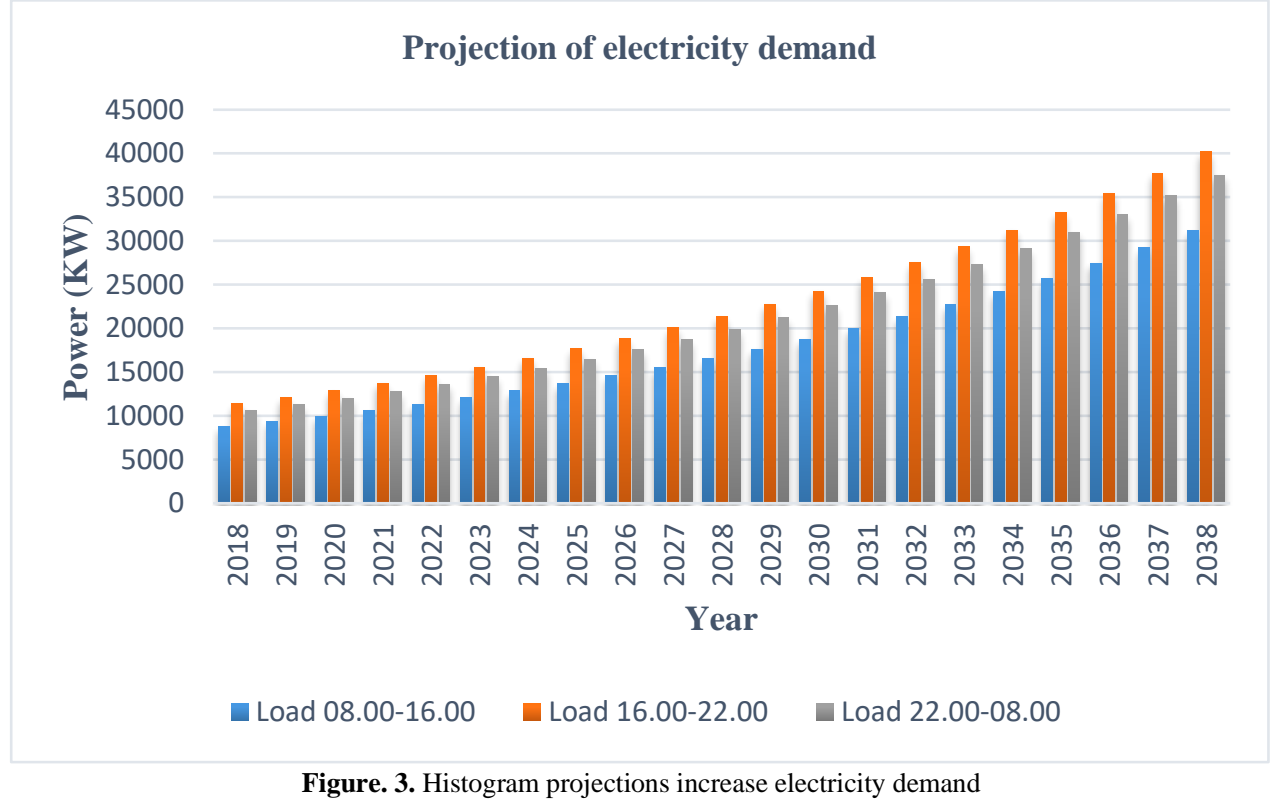

\section{A. Case 1}

In case 1 , an analysis of the existing generator system consisting of 17 units of diesel power plants on the R-day, the 20th hour in 2026. The results of the economic dispatch problem solve by linear programming methodology and comparison with unit commitment improvement are given in Table 1. Then, the results of the 1 st to 24th-hour calculation as a whole are shown in Figure 4.

TABLE 1.

COMPARISON TWO METHODS BY LINEAR PROGRAMMING FOR LOAD IN 2026

\begin{tabular}{ccccccc}
\hline \multirow{2}{*}{ Unit i } & \multicolumn{3}{c}{ Economic Dispatch } & \multicolumn{3}{c}{ Unit Commitment Improvement } \\
\cline { 2 - 7 } & $\begin{array}{c}\text { Power } \\
(\mathrm{KW})\end{array}$ & $\begin{array}{c}\text { Load Factor } \\
(\%)\end{array}$ & $\begin{array}{c}\text { SFCP } \\
(\mathrm{IDR} / \mathrm{KWH})\end{array}$ & $\begin{array}{c}\text { Power } \\
(\mathrm{KW})\end{array}$ & $\begin{array}{c}\text { Load Factor } \\
(\%)\end{array}$ & $\begin{array}{c}\text { SFCP } \\
(\text { IDR/KWH) }\end{array}$ \\
\hline $\mathbf{1}$ & 390 & 65 & 1729 & - & - & - \\
$\mathbf{2}$ & 1020 & 85 & 1550 & 1020 & 85 & 1549.7 \\
$\mathbf{3}$ & 1020 & 85 & 1550 & 1020 & 85 & 1549.7 \\
$\mathbf{4}$ & 1020 & 85 & 1550 & 1020 & 85 & 1549.7 \\
$\mathbf{5}$ & 940 & 78.3 & 1542 & 1018 & 84.8 & 1537.7 \\
$\mathbf{6}$ & 940 & 78.3 & 1542 & 1018 & 84.8 & 1537.7 \\
$\mathbf{7}$ & 940 & 78.3 & 1542 & 1018 & 84.8 & 1537.7 \\
\hline
\end{tabular}




\begin{tabular}{ccccccc}
\hline $\mathbf{8}$ & 940 & 78.3 & 1542 & 1018 & 84.8 & 1537.7 \\
$\mathbf{9}$ & 940 & 78.3 & 1542 & 1018 & 84.8 & 1537.7 \\
$\mathbf{1 0}$ & 1292 & 85 & 1416 & 1292 & 85 & 1415.8 \\
$\mathbf{1 1}$ & 1292 & 85 & 1416 & 1292 & 85 & 1415.8 \\
$\mathbf{1 2}$ & 1292 & 85 & 1416 & 1292 & 85 & 1415.8 \\
$\mathbf{1 3}$ & 1292 & 85 & 1416 & 1292 & 85 & 1415.8 \\
$\mathbf{1 4}$ & 1292 & 85 & 1416 & 1292 & 85 & 1415.8 \\
$\mathbf{1 5}$ & 1292 & 85 & 1416 & 1292 & 85 & 1416 \\
$\mathbf{1 6}$ & 1292 & 85 & 1416 & 1292 & 85 & 1416 \\
$\mathbf{1 7}$ & 1292 & 85 & 1416 & 1292 & 85 & 1416 \\
Total & 18484 & - & 25417 & 18484 & - & 23664 \\
\hline
\end{tabular}

Table 1 is a sample of case 1 in the form of power scheduling generated by Unit $\mathrm{i}$ in the R-day period, the 20th hour in 2026. At the 20th hour, where economic dispatch calculations have the smallest load factor of $65 \%$ and the largest load factor $85 \%$ with an average load factor of $81.85 \%$, while the calculation of unit commitment improvement has the smallest load factor of 84.8 and the largest load factor of $85,00 \%$ with an average load factor of $84.94 \%$.

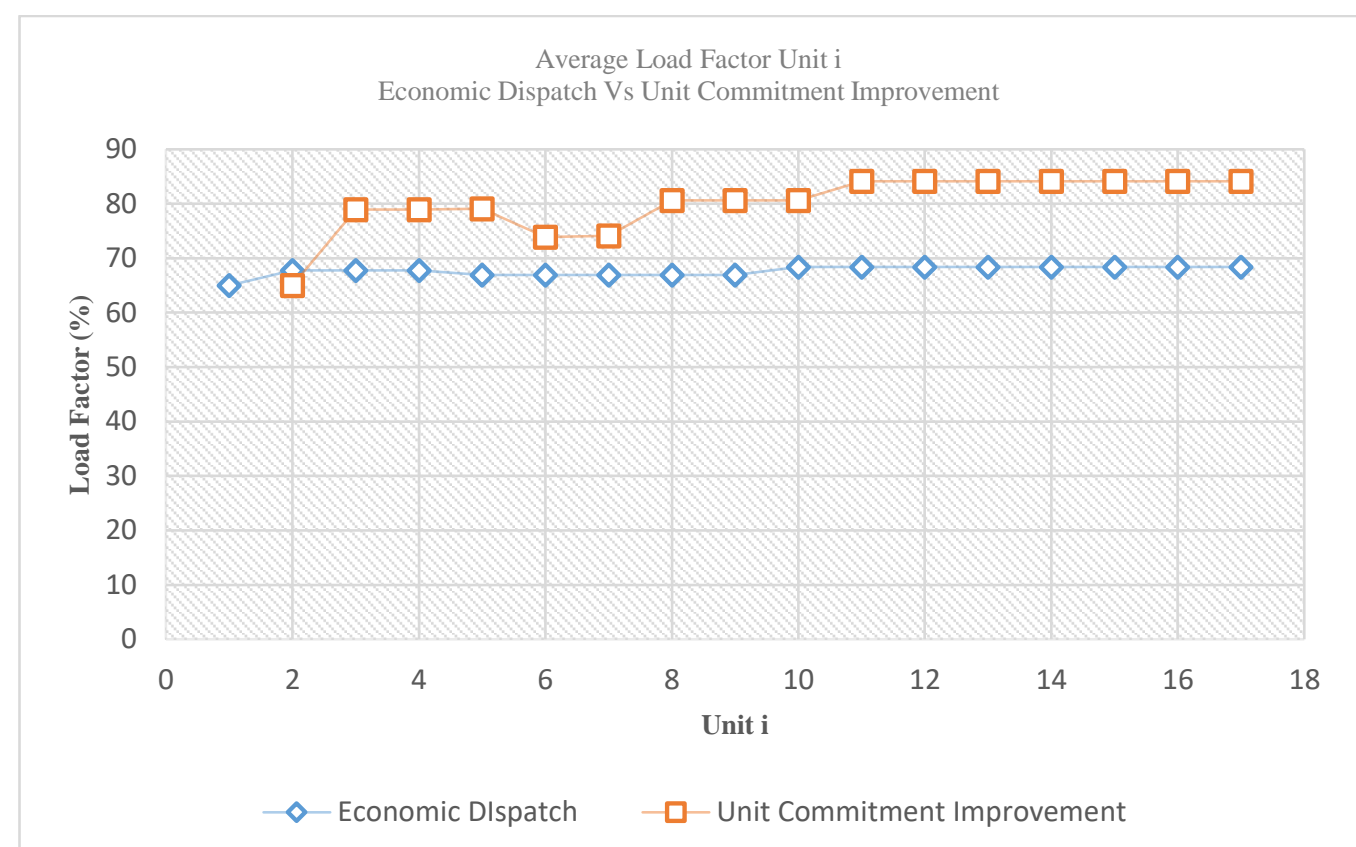

Figure. 4. Graph of comparison between economic dispatch and unit commitment improvement in the R-day period of 2026.

Based on Figure 4 that based on economic dispatch calculations with the smallest average load factor $65.00 \%$ is owned by Unit 1 and the largest load factor average is $68.39 \%$ owned by Unit 10 until Unit 17 with an overall average load factor of $67.63 \%$, while electric power generation is based on unit commitment improvement dispatch with the lowest average load factor of $65.00 \%$ owned by Unit 1 and the largest average load factor of $84.13 \%$ is owned by Unit 10 until Unit 17 and with an overall load factor average $80.29 \%$.

\section{B. Case 2}

In case 2 , the analysis of the hybrid generator system consisted of 17 units of diesel power plants and 2 units of coal-fired steam power plants on the R-day, the 20th hour in 2033. The results of the economic dispatch problem solve by linear programming methodology and comparison with unit commitment improvement are given in Table 2. Then, the results of the 1 st to $24^{\text {th }}$-hour calculation as a whole are shown in Figure 5.

TABLE 2.

COMPARISON TWO METHODS BY LINEAR PROGRAMMING FOR LOAD IN 2033

\begin{tabular}{ccccccc}
\hline \multirow{2}{*}{ Unit i } & \multicolumn{3}{c}{ Economic Dispatch } & \multicolumn{3}{c}{ Unit Commitment Improvement } \\
\cline { 2 - 7 } & $\begin{array}{c}\text { Power } \\
(\mathrm{KW})\end{array}$ & $\begin{array}{c}\text { Load Factor } \\
(\%)\end{array}$ & $\begin{array}{c}\text { SFCP } \\
(\mathrm{IDR} / \mathrm{KWH})\end{array}$ & $\begin{array}{c}\text { Power } \\
(\mathrm{KW})\end{array}$ & $\begin{array}{c}\text { Load Factor } \\
(\%)\end{array}$ & $\begin{array}{c}\text { SFCP } \\
(\mathrm{IDR} / \mathrm{KWH})\end{array}$ \\
\hline $\mathbf{1}$ & 390 & 65.0 & 1729 & - & - & - \\
$\mathbf{2}$ & 900 & 75.0 & 1563 & 982 & 81.8 & 1553.1 \\
\hline
\end{tabular}




\begin{tabular}{rrrrrrr}
\hline $\mathbf{3}$ & 900 & 75.0 & 1563 & 982 & 81.8 & 1553.1 \\
$\mathbf{4}$ & 900 & 75.0 & 1563 & 982 & 81.8 & 1553.1 \\
$\mathbf{5}$ & 780 & 65.0 & 1564 & 900 & 75.0 & 1546.1 \\
$\mathbf{6}$ & 780 & 65.0 & 1564 & 900 & 75.0 & 1546.1 \\
$\mathbf{7}$ & 780 & 65.0 & 1564 & 900 & 75.0 & 1546.1 \\
$\mathbf{8}$ & 780 & 65.0 & 1564 & 900 & 75.0 & 1546.1 \\
$\mathbf{9}$ & 780 & 65.0 & 1564 & - & - & - \\
$\mathbf{1 0}$ & 1236.4 & 81.3 & 1415 & 1292 & 85.0 & 1415.8 \\
$\mathbf{1 1}$ & 1236.4 & 81.3 & 1415 & 1292 & 85.0 & 1415.8 \\
$\mathbf{1 2}$ & 1236.4 & 81.3 & 1415 & 1292 & 85.0 & 1415.8 \\
$\mathbf{1 3}$ & 1236.4 & 81.3 & 1415 & 1292 & 85.0 & 1415.8 \\
$\mathbf{1 4}$ & 1236.4 & 81.3 & 1415 & 1292 & 85.0 & 1415.8 \\
$\mathbf{1 5}$ & 1236.4 & 81.3 & 1415 & 1292 & 85.0 & 1416 \\
$\mathbf{1 6}$ & 1236.4 & 81.3 & 1415 & 1292 & 85.0 & 1416 \\
$\mathbf{1 7}$ & 1236.4 & 81.3 & 1415 & 1292 & 85.0 & 1416 \\
Total & 16881 & - & 25557 & 16881 & - & 22170 \\
\hline
\end{tabular}

Table 2 is a sample of case 2 in the form of power scheduling generated by Unit I in the R-day period, the $20^{\text {th }}$-hour in 2033. At the 20th hour, where economic dispatch calculations have the smallest load factor of $65 \%$ and the largest load factor $81,30 \%$ with an average load factor of $74,50 \%$, while the calculation of unit commitment improvement has the smallest load factor of $75,00 \%$ and the largest load factor of $85,00 \%$ with an average load factor of 81,70

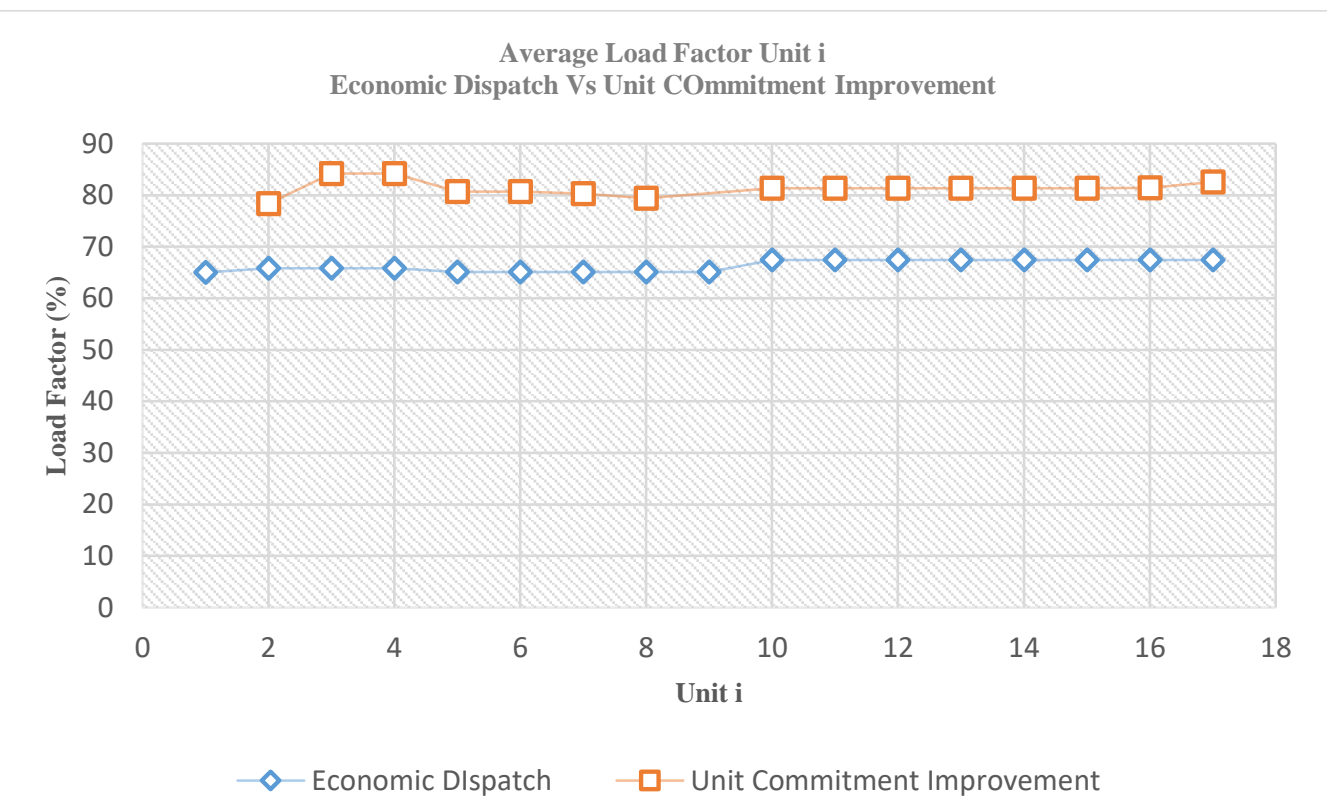

Figure. 5. Graph of comparison between economic dispatch and unit commitment improvement in the R-day period of 2033

Based on Figure 5 that economic dispatch calculations with the lowest average load factor $65.00 \%$ are owned by Unit 1 and the largest load factor average is $67.42 \%$ owned by Unit 10 until Unit 17 with an overall average load factor of $66.30 \%$, while electricity generation is based on unit commitment improvement dispatch with the lowest average load factor of $78.35 \%$ owned by Unit 2 and the largest average load factor of $84.20 \%$ is owned by Unit 3 and Unit 4 where Unit 1 and Unit 9 are not operational so they have an overall average load factor of $81.54 \%$.
C. Case 3

In case 3, the analysis of the hybrid generator system consisted of 17 units of diesel power plants and 4 units of coal-fired steam power plants on the R-day, the 20th hour in 2033. The results of the economic dispatch problem solve by linear programming methodology and comparison with unit commitment improvement are given in Table 4. Then, the results of the 1 st to $24^{\text {th }}$-hour calculation as a whole are shown in Figure 6. 
TABLE 3.

\begin{tabular}{|c|c|c|c|c|c|c|}
\hline \multirow[b]{2}{*}{ Unit i } & \multicolumn{3}{|c|}{ Economic Dispatch } & \multicolumn{3}{|c|}{ Unit Commitment Improvement } \\
\hline & $\begin{array}{l}\text { Power } \\
(\mathrm{KW})\end{array}$ & $\begin{array}{l}\text { Load Factor } \\
(\%)\end{array}$ & $\begin{array}{c}\text { SFCP } \\
(\mathrm{IDR} / \mathrm{KWH})\end{array}$ & $\begin{array}{l}\text { Power } \\
(\mathrm{KW})\end{array}$ & $\begin{array}{l}\text { Load Factor } \\
(\%)\end{array}$ & $\begin{array}{c}\text { SFCP } \\
\text { (IDR/KWH) }\end{array}$ \\
\hline 1 & 390 & 65.0 & 1729 & - & - & - \\
\hline 2 & 780 & 65.0 & 1585 & 900 & 75.0 & 1562.7 \\
\hline 3 & 780 & 65.0 & 1585 & 900 & 75.0 & 1562.7 \\
\hline 4 & 780 & 65.0 & 1585 & 900 & 75.0 & 1562.7 \\
\hline 5 & 780 & 65.0 & 1564 & 884 & 73.7 & 1547.8 \\
\hline 6 & 780 & 65.0 & 1564 & 884 & 73.7 & 1547.8 \\
\hline 7 & 780 & 65.0 & 1564 & 884 & 73.7 & 1547.8 \\
\hline 8 & 780 & 65.0 & 1564 & - & - & - \\
\hline 9 & 780 & 65.0 & 1564 & - & - & - \\
\hline 10 & 1132 & 74.5 & 1418 & 1292 & 85.0 & 1415.8 \\
\hline 11 & 1132 & 74.5 & 1418 & 1292 & 85.0 & 1415.8 \\
\hline 12 & 1132 & 74.5 & 1418 & 1292 & 85.0 & 1415.8 \\
\hline 13 & 1132 & 74.5 & 1418 & 1292 & 85.0 & 1415.8 \\
\hline 14 & 1132 & 74.5 & 1418 & 1292 & 85.0 & 1415.8 \\
\hline 15 & 1132 & 74.5 & 1418 & 1292 & 85.0 & 1416 \\
\hline 16 & 1132 & 74.5 & 1418 & 1292 & 85.0 & 1416 \\
\hline 17 & 1132 & 74.5 & 1418 & 1292 & 85.0 & 1416 \\
\hline Total & 15689 & - & 25643 & 15689 & - & 20658 \\
\hline
\end{tabular}

Table 3 is a sample of case 3 in the form of power scheduling generated by Unit $\mathrm{i}$ in the R-day period, the 20th hour in 2038. At the 20th hour, where economic dispatch calculations have the smallest load factor of $65 \%$ and the largest load factor $74,00 \%$ with an average load factor of $69,50 \%$, while the calculation of commitment has the smallest load factor of $73,70 \%$ and the largest load factor of $85,00 \%$ with an average load factor of $80,40 \%$

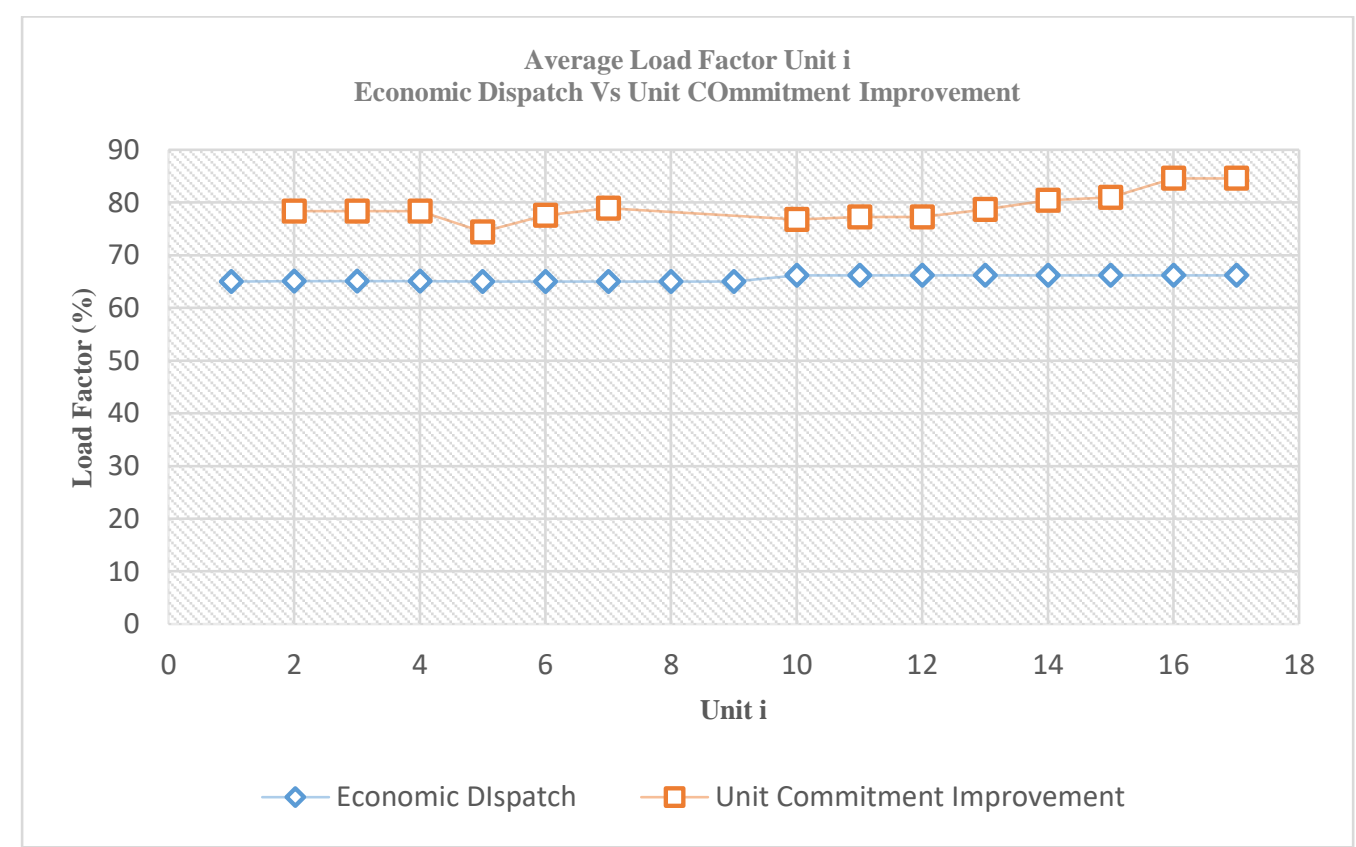

Figure. 6. Graph of comparison between economic dispatch and unit commitment improvement in the R-day period of 2038

From Figure 6 that based on economic dispatch calculations with the smallest load factor average of $65.00 \%$ owned by Unit 1 and the largest average load factor of $66.17 \%$ is owned by Unit 10 , until Unit 17 with an overall average load factor of $65.56 \%$, while electricity generation is based on unit commitment improvement 
with the lowest average load factor of $74.44 \%$ owned by Unit 5 and the largest average load factor of $84.57 \%$ is owned by Unit 16 and Unit 17 where Unit 1, Unit 8 and Unit 9 are not operational at the moment, so they have an overall average load factor of $79.02 \%$.

D. Cost Analysis of Economic Dispatch Calculation
Based on Figure 7 is a graph of the comparison of fuel consumption price (FCP) between using the economical dispatch calculation, unit commitment improvement, and existing. Data on total fuel consumption price with the existing method obtained from the monthly report of the PLN Selatpanjang was taken based on the load in February 2018

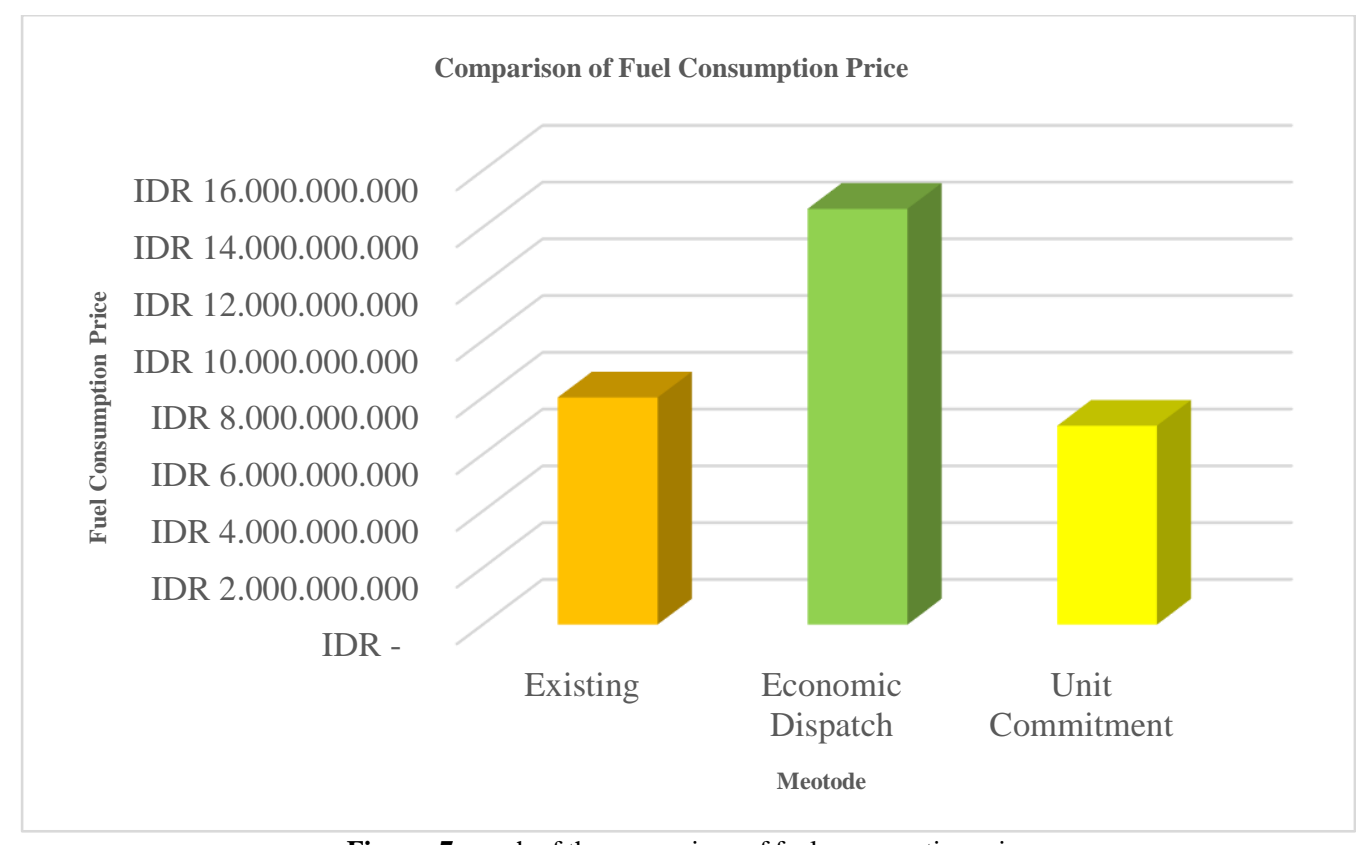

Figure. 7. graph of the comparison of fuel consumption price

Based on Figure 7, it can be seen that the largest fuel consumption price comes from economic dispatch calculations, which are around 14.65 billion rupiahs and the smallest Fuel Consumption Price comes from unit commitment improvement, which is around 7 billion rupiahs. When compared with the existing calculation with an FCP of around 8 billion rupiahs, it will save FCP expenses by around $12.5 \%$ if the unit commitment improvement is implemented. However, when compared

\section{CONCLUSION}

Economic dispatch calculations have a smaller average load factor compared to the average load factor unit commitment improvement. Economic dispatch calculations for existing electricity generation systems, stage I and II hybrid power generation systems have caused existing power plants to decrease line in average load factors from $67.63 \%$ to $66.30 \%$ and $65.56 \%$ respectively. Whereas by using the unit commitment improvement calculation, the average load factor from the existing power plant system increases in the addition of the number of stages I power plants, which is $80.29 \%$ to $81.54 \%$ and has decreased to $79.02 \%$ in stage II. Thus, the generation with economic dispatch will have a higher specific fuel consumption ( $\mathrm{g} / \mathrm{KWH}$ ) than the unit commitment improvement so that the fuel consumption price will be higher. to economic dispatch, it will suffer a loss of around $83.12 \%$. This is because power generation is based on economic dispatch calculations has the average load factor is smaller than the average load factor unit commitment improvement. Thus, generation with economic dispatch will have a higher specific fuel consumption ( $\mathrm{g} / \mathrm{KWH})$ than the unit commitment improvement so that the fuel consumption price will be higher

\section{REFERENCES}

[1] PLN, "Laporan Bulanan Rayon Selatpanjang, Kabupaten kepulauan Meranti, Riau," PLN Rayon Selatpanjnag, Kabupaten Kepulauan Meranti, Riau, Meranti, 2018.

[2] K. ESDM, "Kebijakan Produksi Batubara Nasional dan Kewajiban Dmo," Direktorat Jenderal Mineral dan Batu Bara, Jakarta, 2018.

[3] K. ESDM, "Neraca Gas Bumi Indonesia 2018-2027," Jakarta, 2018.

[4] A. J. Wood, B. F. Wollenberg and G. B. Shable, Power Generation, Operation, and Control, Third ed., 2014.

[5] R. Dogra, N. Gupta and H. Saroa, "Economic Load Dispatch Problem and Matlab Programming of Different Methods," International Conference of Advance Research and Innovation, pp. 202-207, 2014.

[6] R. Balamurugant and S. Subramanian, "An Improved Dynamic Programming Approach to Economic Power Dispatch with Generator Constraints and Transmission Losses," Journal of Electrical Engineering \& Technology, pp. 320-330, 2008.

[7] G. Sreenivasan, S. C.H and S. Sivanagaraju, "Solution of Dynamic Economic Load Dispatch (DELD) Problem with Valve Point Loading Effects and Ramp Rate Limits Using 
PSOInternational," Journal of Electrical and Computer Engineering, no. 1, 2011.

[8] H. Happ, "Optimal power dispatch - a comprehensive survey," IEEE, no. 3, pp. 841-854, 1997.

[9] A. Dutt and A. Dhamanda, "Classical Approach to Solve Economic Load Dispatch Problem of Thermal Generating Unit in MATLAB Programming," International Journal of Engineering Research \& Technology, vol. II, no. 10, 2013.

[10] C. Lewis, "Linear Programming: Theory and Applications," 2008.

[11] S. S. Chavan, N. Raman and T. K. Rajavel, Economic Dispatch and Hydro-Scheduling using Linear Programming, 2011.

[12] J. Kumar, Application of artificial neural networks to Application of artificial neural networks to operation, 1993.

[13] H. Ahmadi, J. R. Marti and A. Moshref, "Piecewise linear approximation of generators cost functions using max-affine functions," IEEE, 2013.

[14] A. Ashaq and A. Z. khan, "Optimization of Economic Load Dispatch Problem by Linear Programming Modified Methodology," International Conference on Emerging Trends in Engineering and Technology, 2014.

[15] B. Kraemer, "Understanding Load Factor about Implications for Specifying Onsite Generators," 2011.

[16] ISO, Reciprocating internal combustion engine driven alternating current generating sets, 2018. 